\title{
Abuse Liability of Prescription Opioids Compared to Heroin in Morphine-Maintained Heroin Abusers
}

\author{
Sandra D Comer*,1,2, Maria A Sullivan ${ }^{1,2}$, Robert A Whittington ${ }^{3}$, Suzanne K Vosburg ${ }^{1,2}$ and \\ William J Kowalczyk $\mathbf{k}^{\mathbf{1}, 2}$
}

'Division on Substance Abuse, New York State Psychiatric Institute, College of Physicians and Surgeons of Columbia University, New York, NY, USA; ${ }^{2}$ Department of Psychiatry, College of Physicians and Surgeons of Columbia University, New York, NY, USA; ${ }^{3}$ Department of Anesthesiology, College of Physicians and Surgeons of Columbia University, New York, NY, USA

\begin{abstract}
Abuse of prescription opioid medications has increased dramatically in the United States during the past decade, as indicated by a variety of epidemiological sources. However, few studies have systematically examined the relative reinforcing effects of commonly abused opioid medications. The current double-blind, placebo-controlled in-patient study was designed to compare the effects of intravenously delivered fentanyl $(0,0.0625,0.125,0.187$, and $0.250 \mathrm{mg} / 70 \mathrm{~kg})$, oxycodone $(0,6.25,12.5,25$, and $50 \mathrm{mg} / 70 \mathrm{~kg})$, morphine $(0,6.25,12.5$, 25 , and $50 \mathrm{mg} / 70 \mathrm{~kg})$, buprenorphine $(0,0.125,0.5,2$, and $8 \mathrm{mg} / 70 \mathrm{~kg})$, and heroin $(0,3.125,6.25,12.5$, and $25 \mathrm{mg} / 70 \mathrm{~kg})$ in morphinemaintained heroin abusers $(N=8$ completers maintained on $120 \mathrm{mg}$ per day oral morphine in divided doses ( $30 \mathrm{mg}$ q.i.d.)). All of the participants received all of the drugs tested; drugs and doses were administered in non-systematic order. All of the drugs produced statistically significant, dose-related increases in positive subjective ratings, such as 'I feel a good drug effect' and 'I like the drug.' In general, the order of potency in producing these effects, from most to least potent, was fentanyl $>$ buprenorphine $\geqslant$ heroin $>$ morphine $=$ oxycodone. In contrast, buprenorphine was the only drug that produced statistically significant increases in ratings of 'I feel a bad drug effect' and it was the only drug that was not self-administered above placebo levels at any dose tested. These data suggest that the abuse liability of buprenorphine in heroin-dependent individuals may be low, despite the fact that it produces increases in positive subjective ratings. The abuse liabilities of fentanyl, morphine, oxycodone, and heroin, however, appear to be similar under these experimental conditions.
\end{abstract}

Neuropsychopharmacology (2008) 33, I I79- II9I; doi: I0.1038/sj.npp. I30 I479; published online 20 June 2007

Keywords: prescription opioid abuse; self-administration; heroin; oxycodone; fentanyl; buprenorphine

\section{INTRODUCTION}

Data from various sources suggest that the abuse of prescription opioids has risen substantially in the United States since the mid-1990s. The National Survey on Drug Use and Health, for example, revealed that the initiation of non-medical use of prescription pain relievers has quadrupled, from an incidence of 573000 in 1990 to 2.5 million in 2002 (SAMHSA, 2004a). Furthermore, the estimated number of new initiates in 2004 to non-medical use of pain relievers (2.4 million) even exceeded that of illicit drugs such as marijuana (2.1 million) and cocaine (1.0 million) (SAMHSA, 2005a). The Monitoring the Future (MTF) survey of high school students recently showed high rates

\footnotetext{
*Correspondence: Dr SD Comer, Department of Psychiatry, The New York State Psychiatric Institute, College of Physicians and Surgeons of Columbia University, I05I Riverside Dr., Unit 120, New York, NY 10032, USA, Tel: + | 212543 598I, Fax: + | 212543599 |, E-mail:sdc10@columbia.edu

Received 12 January 2007; revised I4 May 2007; accepted I5 May 2007
}

of non-medical use of prescription medications, especially opioid painkillers, despite an otherwise general decline in the abuse of illicit drugs among this population (Johnston et al, 2006). Additional evidence supporting a growth in prescription opioid abuse comes from the Treatment Episode Data Set (TEDS), which showed a substantial increase in the proportion of new users of prescription opioids from $26 \%$ in 1997 to $39 \%$ in 2002 (SAMHSA, 2005b). The Drug Abuse Warning Network (DAWN) revealed that from 1995 to 2002, drug abuse-related emergency department visits involving narcotic analgesics increased over 2.5 times, from 42857 to 108320 . More specifically, there was a $159 \%$ increase in hydrocodone mentions, $176 \%$ increase in methadone mentions, and $512 \%$ increase in oxycodone mentions (SAMHSA, 2004b). In the 2003 DAWN report, opiates/opioid analgesics represented roughly $17 \%$ of abuse-related admissions (SAMHSA, 2004c). Taken together, these data reveal that abuse of prescription opioids in the United States has increased substantially in the last decade, which has resulted in sharp rises in morbidity and mortality at the local and national levels. 
Surprisingly, few studies in laboratory animals (Beardsley et al, 2004; Woods et al, 2002) and no studies in humans have been conducted to examine systematically the reinforcing effects of some of the most commonly abused prescription opioids, such as oxycodone. Fentanyl abuse has also increased substantially in the last decade, and although the reinforcing effects of fentanyl have been examined in some detail in laboratory animals (eg Ko et al, 2002; Morgan et al, 2002), few studies have examined its reinforcing effects in humans (Zacny et al, 1996b) and no studies have characterized its reinforcing effects in opioid abusers. Like those of the full mu agonist fentanyl, the reinforcing effects of the partial mu opioid agonist buprenorphine have been studied fairly extensively in laboratory animals (eg Mello et al, 1988; Winger and Woods, 2001). However, only a few studies have examined the reinforcing effects of buprenorphine in human research volunteers (Amass et al, 2000; Comer and Collins, 2002; Comer et al, 2002, 2005). Although reports of buprenorphine abuse have been relatively rare in the United States, several other countries around the world have reported a growing problem with it. Consistent with the epidemiological data, our previous studies showed that buprenorphine was self-administered above placebo levels in non-opioiddependent, recently detoxified individuals (Comer and Collins, 2002; Comer et al, 2002, 2005). The purpose of the present study was to compare the reinforcing, subjective, physiological, and performance effects of fentanyl, oxycodone, buprenorphine, morphine, and heroin in morphine-maintained heroin abusers. Morphine was tested because it is a commonly prescribed opioid and it is typically used as the standard mu opioid agonist in a variety of experimental paradigms. Heroin was tested because it is the standard illicit opioid abused on the streets. Although most prescription opioid abuse occurs via the oral route (SAMHSA, 2006), the intravenous route was tested in the present study to make direct comparisons across drugs (ie buprenorphine has low bioavailability via the oral route). Furthermore, the intravenous route was tested because abuse of prescription opioids often progresses from the oral to the intranasal or intravenous route.

\section{METHODS}

\section{Participants}

Eight heroin-dependent individuals (five men, three women; five White, two Hispanic, one Black), who were currently not seeking treatment for their drug use, completed the 6-week protocol. On average, participants were $39 \pm 2$ years of age (range: $29-44), 71.7 \pm 4.0 \mathrm{~kg}$ in weight (range: 57.7-87.4), $1.72 \pm 0.03 \mathrm{~m}$ in height (range: 1.57-1.82), with a BMI of $24.2 \pm 1.1 \mathrm{~kg} / \mathrm{m}^{2}$ (range: $19.8-$ 29.5). All participants reported daily heroin use by the intravenous route, spent an average of $\$ 65 \pm \$ 10$ per day on heroin, and were physiologically dependent on it upon entry into the study. Heroin was the drug of choice for all participants. In addition, all of the volunteers smoked tobacco cigarettes (10-20 cigarettes per day), four reported using cocaine (three used cocaine once per month and one used cocaine 15 days per month), one drank alcohol daily, one used marijuana every other day, and one used sedatives once per week. Three additional male participants began the study but did not complete it. One discontinued for personal reasons unrelated to the study, one discontinued because of emergent anxiety symptoms after admission, and one discontinued because he decided to seek treatment for his drug use.

After an initial telephone interview, eligible participants received additional screening, which included completing detailed questionnaires on drug use, general health and medical history, and a medical and psychological evaluation. An electrocardiogram and Mantoux test or chest X-ray were also performed. Routine laboratory analyses included a hematology screen, blood chemistry panel, liver function tests, thyroid function tests, syphilis serology, and urinalysis. Urine drug toxicologies (opioids, benzoylecgonine, benzodiazepines, cannabinoids, and amphetamines) were also performed using urine quick tests.

Participants were excluded from the study if they were seeking drug treatment, physiologically dependent on alcohol or illicit drugs other than heroin, or had a major Axis I psychiatric diagnosis other than heroin dependence (eg bipolar disorder, schizophrenia, and major depression). Those who had recent histories of violence or who were on parole/probation were excluded from the study. Participants were required to be physically healthy and fully able to perform all study procedures. They were told that they would receive opioids during the study and that different doses would be tested.

Before admission, participants completed a training session, during which the study procedures were explained to them in detail. Volunteers were paid $\$ 25$ per in-patient day and an additional $\$ 25$ per day bonus if they completed the study. In addition, they could receive an additional $\$ 20$ per experimental session ( $\$ 40$ per day). Participants signed consent forms describing the aims of the study, and the potential risks and benefits of participation. This study was approved by the Institutional Review Board of the New York State Psychiatric Institute.

\section{Apparatus}

During the experimental sessions, participants were seated in a room equipped with Macintosh computers. All vital signs, computer activities, and behaviors were continuously monitored by the experimenters in an adjacent room via vital signs monitors (Criticare Poet Plus 8100 vital signs monitor, Critical Systems Inc., Waukesha, WI), a continuous online computer network, and a one-way mirror. Communication between the staff and participants was kept to a minimum during experimental sessions.

\section{Experimental Sessions}

During all laboratory sessions, participants completed computerized tasks and subjective-effect questionnaires. For the safety of the participants, a physician remained in the laboratory space for $15 \mathrm{~min}$ after drug administration and remained in the building, accessible by beeper, for $1 \mathrm{~h}$ after drug administration. A pulse oximeter continuously monitored $\% \mathrm{SpO}_{2}$ during sessions, and heart rate, systolic blood pressure, and diastolic blood pressure were measured 
every $5 \mathrm{~min}$ throughout laboratory sessions. Pupil photographs were taken repeatedly.

There were two types of laboratory sessions: a morning sample session and an afternoon choice session (see below). The duration of each session was approximately $120 \mathrm{~min}$.

\section{Sample Session}

Physiological, subjective, and performance effects were measured before and repeatedly after drug administration. Following the baseline measures, drug and $\$ 20$ were administered simultaneously at time 0 min, provided that oxygenation was sufficient $\left(\% \mathrm{SpO}_{2}>93 \%\right)$. A photograph was taken of the right pupil before and $4,10,40$, and $60 \mathrm{~min}$ after drug administration. A subjective-effects battery was administered before and 4, 40,90, 150, and $210 \mathrm{~min}$ after drug administration. A performance battery was administered before and 10, 60, 120, and $180 \mathrm{~min}$ after drug administration. The Subjective Opioid Withdrawal Scale (SOWS) was administered before and $180 \mathrm{~min}$ after drug administration. The Drug Effect Questionnaire (DEQ) was administered 4, 10, 60, 120, and $180 \mathrm{~min}$ after drug administration.

\section{Choice Session}

Choice sessions were similar in design to sample sessions, except that participants completed a self-administration task (see below) after the baseline assessments. Participants were instructed to choose between tenths of $\$ 20$ and the dose that they had received during the sample session. A pupil photograph was taken before drug administration. The subjective-effects battery was administered before, and 4 and $40 \mathrm{~min}$ after drug administration. The performance battery was completed before and $10 \mathrm{~min}$ after drug administration. The SOWS was completed before drug administration. The DEQ was completed before and $10 \mathrm{~min}$ after drug administration. Choice sessions were otherwise identical to sample sessions.

\section{Self-Administration}

During choice sessions, participants were told that they could work for all or part of the sampled dose or the sampled money amount (\$20) by choosing the drug or money option each time a choice was available. The alternative money value ( $\$ 20)$ was chosen based on previous studies conducted in our laboratory (Comer et al, 1997, 1998) showing that the dose-response curve for heroin was the most lawful when this money value was used. Responses consisted of finger pressing on a computer mouse. Standardized instructions were read to each participant explaining the self-administration task. Drug and money were available at each choice trial. Thus, if the dose for that day was $8 \mathrm{mg}$, at each opportunity participants could respond for $0.8 \mathrm{mg}(10 \%$ of $8 \mathrm{mg})$ or $\$ 2(10 \%$ of $\$ 20)$. Completion of the ratio requirement for each choice trial was accompanied by a visual stimulus on the computer screen. After a choice was made for one option, responding for the other option was not possible until the ratio was completed and another trial was initiated. The response requirement for each of the two options increased independently such that the initial ratio requirement for each option was 50 responses; the ratio increased progressively each time the option was selected $(50,100,200,400$, $800,1200,1600,2000,2400$, and 2800). To receive all of the drug or money available that day, participants were required to emit 11550 responses within $40 \mathrm{~min}$. Fewer total responses were required if choices were distributed between the two options. These ratio values were chosen based on previous research conducted in our laboratory (eg Comer et al, 1999). Participants were choosing between drug and money at each trial, so the drug and money breakpoint values generally were inversely related. Although sustained high rates of responding were required, participants were capable of completing 11550 responses in the allotted time.

At the start of each self-administration task, two illustrations appeared on the computer screen: an empty balance scale and an empty bank. As each choice trial was completed, either the scale was implemented with a pile of powder or a dollar sign was added to the bank. Thus participants could always see how many money and drug choices had been made. At the end of the 40-min selfadministration task, the participant received whatever he/she had chosen: money and/or drug.

\section{Subjective Effects}

Four questionnaires were used to assess subjective effects (see Comer et al, 1999 for details). The first questionnaire was a 26-item visual analog scale (VAS) designed to assess subjective and physiological effects. The first 18 lines were labeled with adjectives describing mood states (eg 'I feel...' 'mellow') and four additional lines were labeled with questions about the dose just received (eg 'I liked the dose,' 'For this dose, I would pay...'). Participants also indicated, by making a mark along a $100 \mathrm{~mm}$ line, how much they 'wanted' each of the following drugs: heroin, cocaine, alcohol, and tobacco. Participants rated each item on the visual analog scale from 'Not at all' $(0 \mathrm{~mm})$ to 'Extremely' $(100 \mathrm{~mm})$, except for the 'For this dose, I would pay' question, which ranged between $\$ 0(0 \mathrm{~mm})$ and $\$ 20$ $(100 \mathrm{~mm})$. The second questionnaire was a 13-item opioid symptom checklist consisting of true/false questions designed to measure opioid effects (eg 'My skin is itchy'). The visual analog scale and opioid symptom checklist together constituted the subjective-effects battery. The third questionnaire was the 16-item SOWS. Participants rated each item on a scale from 0 to 4 , with 0 being 'Not at all' and 4 being 'Extremely' (eg 'I have gooseflesh,' etc). The fourth questionnaire was a six-item DEQ. Participants described drug effects by selecting among a series of possible answers ranging from 0 ('No (good, bad, etc) effects at all') to 4 ('Very strong effects'). Ratings of drug liking ranged between -4 ('Dislike very much') and 4 ('Like very much').

\section{Performance Effects}

The task battery consisted of four tasks: a 3-min digitsymbol substitution task, a 10-min divided attention task, a 10-min rapid information-processing task, and a 3-min repeated acquisition of response sequences task (custommade software was used for the performance tasks; see 
Comer et al, 1999 for details). Briefly, the digit-symbol substitution task consisted of nine 3-row by 3-column squares (with one black square per row) displayed across the top of the computer screen. A randomly generated number indicated which of the nine patterns should be emulated on a keypad by the participant on a particular trial. Participants were required to emulate as many patterns as possible by entering the pattern associated with randomly generated numbers appearing on the bottom of the screen. The divided attention task consisted of concurrent pursuit-tracking and vigilance components. Participants tracked a moving stimulus on the video screen using the mouse and also signaled when a small black square appeared at any of the four corners of the video screen. The distance between the cursor and moving stimulus was measured, as was the speed of the moving stimulus (with greater accuracy, the stimulus moved at a faster rate). During the rapid information-processing task, a series of digits was displayed rapidly on the computer screen (100 digits/min), and the participants were instructed to press a key as quickly as possible after three consecutive odd or even digits. During the repeated acquisition of response sequences task, four buttons were illuminated and participants were instructed to learn a 10-response sequence of button presses. A position counter incremented by one each time a correct button was pressed, and remained unchanged whenever the participant responded with an incorrect button. A points counter increased by one each time the 10-response sequence was correctly completed. The sequence remained the same throughout the 3min task, but a new, random sequence was generated every time the task occurred again. Participants were instructed to earn as many points as possible during the 3-min task, by pressing the buttons in the correct sequence.

\section{Physiological Effects}

A blood pressure cuff was attached to the non-dominant arm, and blood pressure was recorded automatically every 5 min. Participants were also connected to a pulse oximeter via a soft sensor on a finger of the non-dominant hand, which continuously monitored $\% \mathrm{SpO}_{2}$ (an indirect measure of arterial blood oxygen saturation). For safety, supplemental oxygen $(2 \mathrm{l} / \mathrm{min})$ was provided via a nasal cannula during all experimental sessions. If $\% \mathrm{SpO}_{2}$ decreased below $93 \%$, breaths were prompted verbally by staff and the oxygen flow rate was increased. A Canon Powershot G2 camera with a Canon Zoom Lens 7-21 MM 1:2.0-2.5 was used to take pupil photographs. All photographs were taken under ambient lighting conditions.

\section{Drugs}

All participants were maintained on $120 \mathrm{mg}$ per day morphine delivered orally ( $30 \mathrm{mg}$ q.i.d., p.o. at 0700, 1300, 1800 , and 2200 hours) throughout the study. Participants were stabilized on morphine for an average of 5 days (range: 4-6 days) before the start of experimental sessions. The test drugs were administered intravenously at approximately 1100 and 1600 hours during laboratory sessions, which occurred twice daily, once in the morning and once in the afternoon, on Mondays through Fridays. One drug was tested each week and one dose was tested each day. Drugs and doses were administered in non-systematic order both within and across participants, with the exception that the highest dose of each drug was not tested first. For safety, the first two participants received fentanyl in ascending order. The test drugs and doses were the following: fentanyl $(0,0.0625,0.125,0.187$, and $0.250 \mathrm{mg} / 70 \mathrm{~kg})$, oxycodone $(0$, $6.25,12.5,25$, and $50 \mathrm{mg} / 70 \mathrm{~kg})$, morphine $(0,6.25,12.5,25$, and $50 \mathrm{mg} / 70 \mathrm{~kg})$, buprenorphine $(0,0.125,0.5,2$, and $8 \mathrm{mg} /$ $70 \mathrm{~kg})$, and heroin $(0,3.125,6.25,12.5$, and $25 \mathrm{mg} / 70 \mathrm{~kg})$. For safety, all of the active fentanyl doses were administered by an experienced anesthesiologist (RAW). The highest fentanyl doses were selected based on previous studies showing that they were safe, well tolerated and behaviorally active (Manner et al, 1987; Zacny et al, 1992). The highest heroin doses were chosen based on several previous studies conducted in our laboratory showing that they were well tolerated, and behaviorally active (eg Comer et al, 1999). The morphine doses were selected based on previous studies demonstrating a two-fold difference in potency between intravenously delivered morphine and heroin (Jasinski and Preston, 1986). The oxycodone doses were chosen based on previous studies demonstrating a roughly equipotent relationship between intravenously delivered oxycodone and morphine for treating pain (Foley, 1985). The highest buprenorphine doses were chosen based on several previous studies conducted in our laboratory demonstrating that they were well tolerated and behaviorally active (Comer and Collins, 2002; Comer et al, 2002, 2005).

Buprenorphine $\mathrm{HCl}(4 \mathrm{mg} / \mathrm{ml})$ for injection and heroin $\mathrm{HCl}$ powder were provided by the National Institute on Drug Abuse (Rockville, MD). Fentanyl citrate $(0.05 \mathrm{mg} / \mathrm{ml})$ and morphine sulfate $(15 \mathrm{mg} / \mathrm{ml})$ for injection were obtained from Cardinal Distribution Company (Syracuse, $\mathrm{NY})$. Oxycodone $\mathrm{HCl}(10 \mathrm{mg} / \mathrm{ml})$ for injection was obtained from Purdue Pharma L.P. (Ardsley, NY). Naloxone $\mathrm{HCl}$ (Narcan ${ }^{\mathrm{B}}$ ) for injection was obtained from DuPont Pharma (Wilmington, DE). Heroin $\mathrm{HCl}(25 \mathrm{mg} / \mathrm{ml})$ for injection was manufactured by the New York State Psychiatric Institute Pharmacy utilizing 5\% dextrose injection USP. All medications were diluted with $0.9 \%$ sodium chloride to achieve a final injection volume of $10 \mathrm{ml}$. Doses were administered on a $\mathrm{mg} / 70 \mathrm{~kg}$ basis. Placebo or active drug was administered intravenously through a catheter via an infusion pump over a 2-min period. Physiologic saline solution was infused continuously during experimental sessions, except during drug administration. Between 1 and $2 \mathrm{ml}$ heparinized saline (10 units $/ \mathrm{ml}$ ) was flushed into the catheter 4-8 times each day. All venous catheters were maintained as heparin locks and were removed within $36 \mathrm{~h}$ of insertion.

Supplemental medications available to all participants for the duration of the study included: calcium carbonate (Mylanta ${ }^{\mathbb{R}}$ ), acetaminophen, ibuprofen, docusate sodium (Colace $^{\circledR}$ ), magnesium hydroxide (Milk of Magnesia ${ }^{\circledR}$ ), and multivitamins with iron. Prochlorperazine and ondansetron were available for nausea, loperamide was offered for diarrhea, and ketorolac tromethamine was provided for muscle pain during the first week after admission. Trazodone, zolpidem, mirtazapine, or clonazepam was available if participants reported having trouble sleeping. All of the participants used trazodone (mean: 32 occasions; 
range: 6-43) and clonazepam (mean: 13 occasions; range 1-26). Five participants used zolpidem (mean: 8 occasions; range: $2-20$ ), six used ibuprofen (mean: 4 occasions; range: 1-11), five used acetaminophen (mean: 3 occasions; range: 1-6), five used clonidine (mean: 3 occasions; range: 1-8), three used magnesium hydroxide (mean: 9 occasions; range: $1-24 \mathrm{cc}$ ), two used nicotine patches (mean: 21 occasions; range: 1-40), and two used prochlorperazine (mean: 5 occasions; range: 1-8). One participant used multivitamins on a daily basis, one used ondansetron on a few occasions, one used loperamide on two occasions, one used mirtazapine on multiple occasions, one used diphenhydramine on one occasion, one used ketorolac on multiple occasions, and one used lorazepam on one occasion. To reduce their impact on our study measures, these medications, when needed, were given only during the evening hours.

Urine samples were collected weekly throughout the study to screen for the presence of other illicit substances. No illicit substances, other than opioids, were found in the participants' urine.

\section{Statistical Analysis}

Repeated measures analyses of variance (ANOVAs) were performed for progressive-ratio break-point values (the highest ratio that participants completed) as a function of drug and dose. Planned comparisons were made between each active dose for each drug and its corresponding placebo dose. Repeated measures ANOVAs were also performed for mean trough pupil diameter, peak task performance, and peak subjective ratings during the sample session as a function of drug and dose. Repeated measures ANOVAs were performed for mean respiratory rate, $\% \mathrm{SpO}_{2}$, end tidal $\mathrm{CO}_{2}$, systolic pressure, diastolic pressure, and mean arterial pressure as a function of drug and dose. $P$-values $<0.05$ were considered statistically significant. Relative potency comparisons were planned for this study, but because the slope of the dose-response curve for buprenorphine was different from the other drugs for many of the measures and because the dose range for fentanyl produced low to moderate effects, we decided not to report formal potency comparisons in the present paper.

\section{RESULTS}

Please note that with the exception of the self-administration data, which were collected during the afternoon choice session, all of the effects that are reported below were collected during the morning sample session.

\section{Subjective Effects}

Visual Analog Scales. All of the drugs produced statistically significant, dose-related increases in mean peak VAS ratings of 'I feel a good drug effect,' 'I like the choice,' 'I feel high,' and 'The choice is of high quality' (Figure 1, Table 1). Peak ratings tended to be highest for heroin, morphine, and oxycodone. Peak ratings for fentanyl and buprenorphine generally were similar to each other and slightly lower than for the other drugs. For example, post hoc comparisons revealed that for ratings of 'I feel high' and amount they
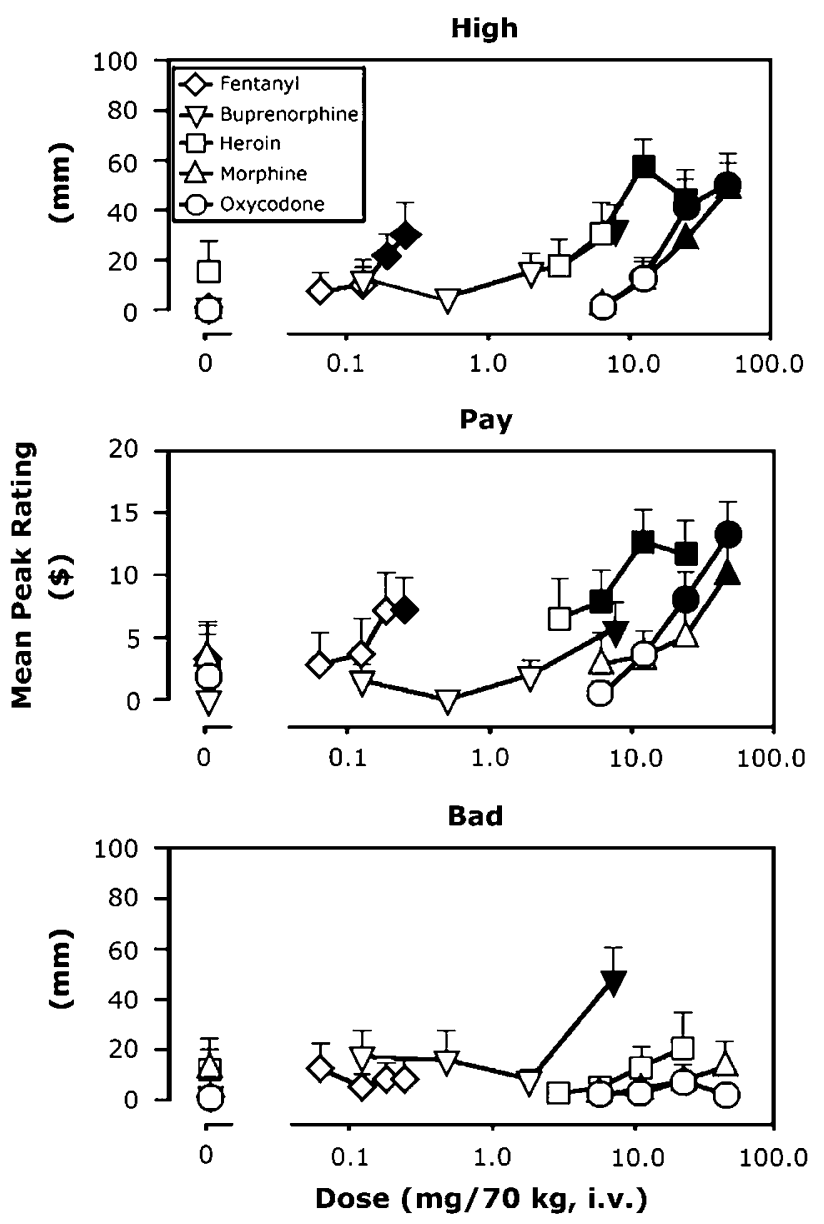

Figure I Selected VAS ratings completed during sample sessions as a function of drug and dose. Data points represent the mean peak ratings \pm I SEM. Filled symbols indicate significant differences from the placebo dose for that drug $(N=8)$.

would be willing to pay for the drug (Table 1), both buprenorphine $(8 \mathrm{mg} / 70 \mathrm{~kg})$ and fentanyl $(0.25 \mathrm{mg} / 70 \mathrm{~kg})$ generally were significantly lower than heroin $(12.5 \mathrm{mg} /$ $70 \mathrm{~kg})$, morphine $(50 \mathrm{mg} / 70 \mathrm{~kg})$, and oxycodone $(50 \mathrm{mg} /$ $70 \mathrm{~kg}$ ). For good drug effects, ratings after administration of the $12.5 \mathrm{mg} / 70 \mathrm{~kg}$ dose of heroin were significantly higher than for $8 \mathrm{mg} / 70 \mathrm{~kg}$ buprenorphine, but not for $0.25 \mathrm{mg} /$ $70 \mathrm{~kg}$ fentanyl. An almost identical pattern of results was obtained for ratings of drug liking, with significant differences between $12.5 \mathrm{mg} / 70 \mathrm{~kg}$ heroin and $8 \mathrm{mg} / 70 \mathrm{~kg}$ buprenorphine, but not $0.25 \mathrm{mg} / 70 \mathrm{~kg}$ fentanyl. Interestingly, ratings of drug quality were not significantly different among buprenorphine $(8 \mathrm{mg} / 70 \mathrm{~kg})$, fentanyl $(0.25 \mathrm{mg} /$ $70 \mathrm{~kg})$, heroin $(12.5 \mathrm{mg} / 70 \mathrm{~kg})$, morphine $(50 \mathrm{mg} / 70 \mathrm{~kg})$, and oxycodone $(50 \mathrm{mg} / 70 \mathrm{~kg})$.

Participants reported that they would pay between $\$ 10$ and $\$ 15$ for the highest doses of heroin, morphine, and oxycodone, and between $\$ 5$ and $\$ 10$ for the highest doses of fentanyl and buprenorphine (middle panel of Figure 1; Table 1). For all of the positive subjective responses shown in Figure 1 and Table 1, ratings were slightly lower, but not significantly so, after administration of $25 \mathrm{mg} / 70 \mathrm{~kg}$ heroin compared to $12.5 \mathrm{mg} / 70 \mathrm{~kg}$ heroin. This decrease in effect at 
Table I Selected Mean Peak Visual Analog Scale Ratings ( \pm I Standard Error of the Mean (SEM)) for Heroin, Morphine, Oxycodone, Fentanyl and Buprenorphine $(N=8)$

\begin{tabular}{|c|c|c|c|c|c|c|c|c|c|c|}
\hline \multirow[b]{2}{*}{ Heroin } & \multicolumn{2}{|c|}{0.0} & \multicolumn{2}{|c|}{3.125} & \multicolumn{2}{|c|}{6.25} & \multicolumn{2}{|c|}{12.5} & \multicolumn{2}{|c|}{25} \\
\hline & Mean & SEM & Mean & SEM & Mean & SEM & Mean & SEM & Mean & SEM \\
\hline Good effect & 12.4 & 10.8 & 21.0 & 12.0 & $31.8^{\mathrm{a}}$ & 13.3 & $61.1^{\mathrm{a}}$ & 10.3 & $52.0^{\mathrm{a}}$ & 12.6 \\
\hline High & 14.1 & 12.3 & 15.9 & 11.1 & 29.8 & 12.2 & $57.4^{\mathrm{a}}$ & 10.3 & $43.9^{\mathrm{a}}$ & 11.4 \\
\hline Mellow & 23.6 & 10.3 & $41.3^{\mathrm{a}}$ & 11.8 & $48.9^{\mathrm{a}}$ & 9.9 & $54.5^{\mathrm{a}}$ & 10.6 & $45.6^{\mathrm{a}}$ & 11.3 \\
\hline Nauseated & 11.3 & 8.3 & 10.9 & 7.3 & 10.3 & 8.3 & 12.5 & 8.5 & 17.6 & 11.1 \\
\hline Potent & 12.3 & 12.3 & 20.8 & 13.9 & $31.0^{\mathrm{a}}$ & 13.1 & 53.6 & 12.6 & $46.9^{a}$ & 11.8 \\
\hline Quality & 12.1 & 12.0 & 23.1 & 13.1 & 32.0 & 13.5 & 57.8 & 12.5 & $48.0^{a}$ & 11.6 \\
\hline Sedated & 21.4 & 14.3 & 20.8 & 12.8 & 26.9 & 14.0 & $50.4^{\mathrm{a}}$ & 11.3 & $39.4^{\mathrm{a}}$ & 9.7 \\
\hline Want heroin & 63.9 & 14.3 & 62.3 & 15.1 & 62.8 & 15.6 & 53.6 & 12.2 & 59.8 & 16.0 \\
\hline \multirow[t]{2}{*}{ Would pay } & 2.8 & 2.5 & 6.6 & 3.1 & $7.2^{\mathrm{a}}$ & 2.5 & $12.8^{\mathrm{a}}$ & 2.5 & $11.6^{\mathrm{a}}$ & 2.7 \\
\hline & \multicolumn{2}{|c|}{0.0} & \multicolumn{2}{|c|}{6.25} & \multicolumn{2}{|c|}{12.5} & \multicolumn{2}{|c|}{25} & \multicolumn{2}{|c|}{50} \\
\hline Morphine & Mean & SEM & Mean & SEM & Mean & SEM & Mean & SEM & Mean & SEM \\
\hline Bad effect & 11.6 & 11.3 & 1.4 & 1.1 & 4.1 & 2.7 & 7.6 & 5.4 & 12.4 & 9.8 \\
\hline Good effect & 0.4 & 0.3 & 1.6 & 1.5 & 17.1 & 10.4 & $35.8^{\mathrm{a}}$ & 12.3 & $57.8^{\mathrm{a}}$ & 14.4 \\
\hline High & 0.5 & 0.3 & 1.8 & 1.6 & 10.5 & 7.6 & $27.9^{a}$ & 10.1 & $48.1^{a}$ & 13.9 \\
\hline Irritable & 50.4 & 15.6 & 31.0 & 13.4 & 43.4 & 15.4 & $27.4^{\mathrm{a}}$ & 11.4 & $24.3^{\mathrm{a}}$ & 14.3 \\
\hline Stimulated & 10.8 & 7.7 & 16.4 & 8.3 & 24 & 9.3 & $29.4^{\mathrm{a}}$ & 10.5 & $47.5^{\mathrm{a}}$ & 14.0 \\
\hline Talkative & 14.8 & 7.9 & 16.4 & 6.9 & 20.8 & 8.4 & $33.6^{\mathrm{a}}$ & 10.4 & $36.3^{\mathrm{a}}$ & 12.2 \\
\hline Want heroin & 49.1 & 17.1 & $66.3^{\mathrm{a}}$ & 16.3 & $71.4^{\mathrm{a}}$ & 15.2 & $65.9^{\mathrm{a}}$ & 13.5 & 53.8 & 16.0 \\
\hline \multirow[t]{2}{*}{ Would pay } & 3.6 & 2.6 & 2.9 & 2.5 & 3.2 & 1.4 & 5.1 & 1.9 & $10.5^{\mathrm{a}}$ & 2.6 \\
\hline & \multicolumn{2}{|c|}{0.0} & \multicolumn{2}{|c|}{6.25} & \multicolumn{2}{|c|}{12.5} & \multicolumn{2}{|c|}{25} & \multicolumn{2}{|c|}{50} \\
\hline Oxycodone & Mean & SEM & Mean & SEM & Mean & SEM & Mean & SEM & Mean & SEM \\
\hline Bad effect & 0.0 & 0.0 & 0.0 & 0.0 & 0.5 & 0.5 & 6.4 & 6.4 & 0.0 & 0.0 \\
\hline Good effect & 0.1 & 0.1 & 4.6 & 3.3 & $18.1^{\mathrm{a}}$ & 8.1 & $49.6^{\mathrm{a}}$ & 11.5 & $54.9^{\mathrm{a}}$ & 11.9 \\
\hline High & 0.0 & 0.0 & 0.6 & 0.5 & 12.1 & 7.7 & $40.9^{\mathrm{a}}$ & 10.5 & $48.9^{\mathrm{a}}$ & 9.4 \\
\hline Irritable & 40.5 & 16.3 & 35.6 & 15.7 & 40.3 & 16.7 & 23.4 & 13.9 & $13.0^{\mathrm{a}}$ & 9.3 \\
\hline Like & 1.5 & 1.5 & 7.9 & 6.2 & 19.5 & 8.3 & $50.4^{\mathrm{a}}$ & 10.4 & $61.5^{\mathrm{a}}$ & 12.6 \\
\hline Mellow & 29.8 & 8.7 & 37.6 & 11.8 & 37.9 & 8.8 & $47.9^{\mathrm{a}}$ & 9.1 & $46.8^{\mathrm{a}}$ & 8.3 \\
\hline Nauseated & 0.0 & 0.0 & 7.5 & 7.5 & 10.1 & 10.1 & 9.1 & 8.8 & 9.3 & 8.3 \\
\hline Potent & 0.3 & 0.3 & 3.8 & 3.6 & 11.6 & 5.1 & $33.9^{\mathrm{a}}$ & 10.9 & $49.3^{\mathrm{a}}$ & 10.1 \\
\hline Quality & 2.1 & 2.1 & 4.5 & 4.2 & 17.6 & 7.3 & $42.0^{\mathrm{a}}$ & 10.4 & $51.3^{\mathrm{a}}$ & 11.1 \\
\hline Sedated & 8.4 & 8.0 & 10.8 & 8.1 & 11.8 & 4.8 & $35.9^{a}$ & 7.3 & $45.1^{\mathrm{a}}$ & 10.2 \\
\hline Social & 15.5 & 7.3 & 17.4 & 7.2 & 26.4 & 7.6 & $35.6^{\mathrm{a}}$ & 8.8 & $34.4^{\mathrm{a}}$ & 8.8 \\
\hline
\end{tabular}


Table I Continued

\begin{tabular}{|c|c|c|c|c|c|c|c|c|c|c|}
\hline Oxycodone & \multicolumn{2}{|c|}{0.0} & \multicolumn{2}{|c|}{6.25} & \multicolumn{2}{|c|}{12.5} & \multicolumn{2}{|c|}{25} & \multicolumn{2}{|c|}{50} \\
\hline Talkative & 18.6 & 8.9 & 17.1 & 7.2 & 21.6 & 6.7 & $43.3^{\mathrm{a}}$ & 10.5 & 35.1 & 9.6 \\
\hline Want heroin & 59.1 & 17.6 & 54.4 & 17.7 & 69.3 & 15.7 & 67.3 & 16.3 & 67.0 & 16.6 \\
\hline \multirow[t]{2}{*}{ Would pay } & 1.8 & 1.6 & 0.9 & 0.6 & 3.8 & 1.7 & $8.0^{\mathrm{a}}$ & 2.2 & $13.4^{\mathrm{a}}$ & 2.5 \\
\hline & \multicolumn{2}{|c|}{0.0} & \multicolumn{2}{|c|}{0.0625} & \multicolumn{2}{|c|}{0.125} & \multicolumn{2}{|c|}{0.187} & \multicolumn{2}{|c|}{0.25} \\
\hline Fentanyl & Mean & SEM & Mean & SEM & Mean & SEM & Mean & SEM & Mean & SEM \\
\hline Bad effect & 0 & 0.0 & 10.4 & 10.4 & 5.3 & 4.2 & 6.1 & 6.1 & 8.3 & 7.2 \\
\hline Good effect & 0.1 & 0.1 & 1.1 & 0.8 & 4.6 & 2.3 & $27.3^{\mathrm{a}}$ & 9.8 & $46.3^{\mathrm{a}}$ & 10.5 \\
\hline Nauseated & 12.6 & 12.5 & 9.9 & 9.9 & 18.6 & 12.2 & 8.4 & 8.4 & 9.6 & 8.3 \\
\hline Potent & 0.0 & 0.0 & 0.6 & 0.4 & 2.4 & 1.5 & $27.5^{\mathrm{a}}$ & 9.2 & $31.0^{\mathrm{a}, \mathrm{c}, \mathrm{d}}$ & 12.6 \\
\hline Quality & 12.5 & 12.5 & 13.4 & 12.4 & 15.4 & 12.2 & 26.0 & 13.5 & $38.4^{\mathrm{a}}$ & 12.2 \\
\hline Sedated & 2.8 & 2.6 & 8.5 & 8.5 & 12.0 & 9.5 & $20.8^{\mathrm{a}}$ & 10.0 & $35.4^{\mathrm{a}}$ & 9.0 \\
\hline Social & 17.0 & 8.6 & 17.6 & 9.6 & 29.1 & 10.3 & $47.5^{a}$ & 12.2 & $36.1^{\mathrm{a}}$ & 14.6 \\
\hline Stimulated & 10.9 & 7.7 & 17.1 & 9.4 & 17.1 & 7.7 & $29.3^{\mathrm{a}}$ & 10.2 & $37.8^{\mathrm{a}}$ & 12.1 \\
\hline Talkative & 13.5 & 7.0 & 18.1 & 9.7 & 23.8 & 11.4 & $40.3^{a}$ & 13.0 & $39.1^{\mathrm{a}}$ & 14.8 \\
\hline Want heroin & 52.0 & 16.5 & 56.4 & 17.5 & 57.8 & 16.7 & 57.9 & 17.5 & $70.3^{\mathrm{a}}$ & 12.5 \\
\hline Would pay & 2.5 & 2.5 & 2.6 & 2.5 & 3.0 & 2.4 & $8.0^{\mathrm{a}}$ & 2.7 & $8.5^{\mathrm{a}, \mathrm{b}, \mathrm{d}}$ & 2.0 \\
\hline
\end{tabular}

0.5

2

8

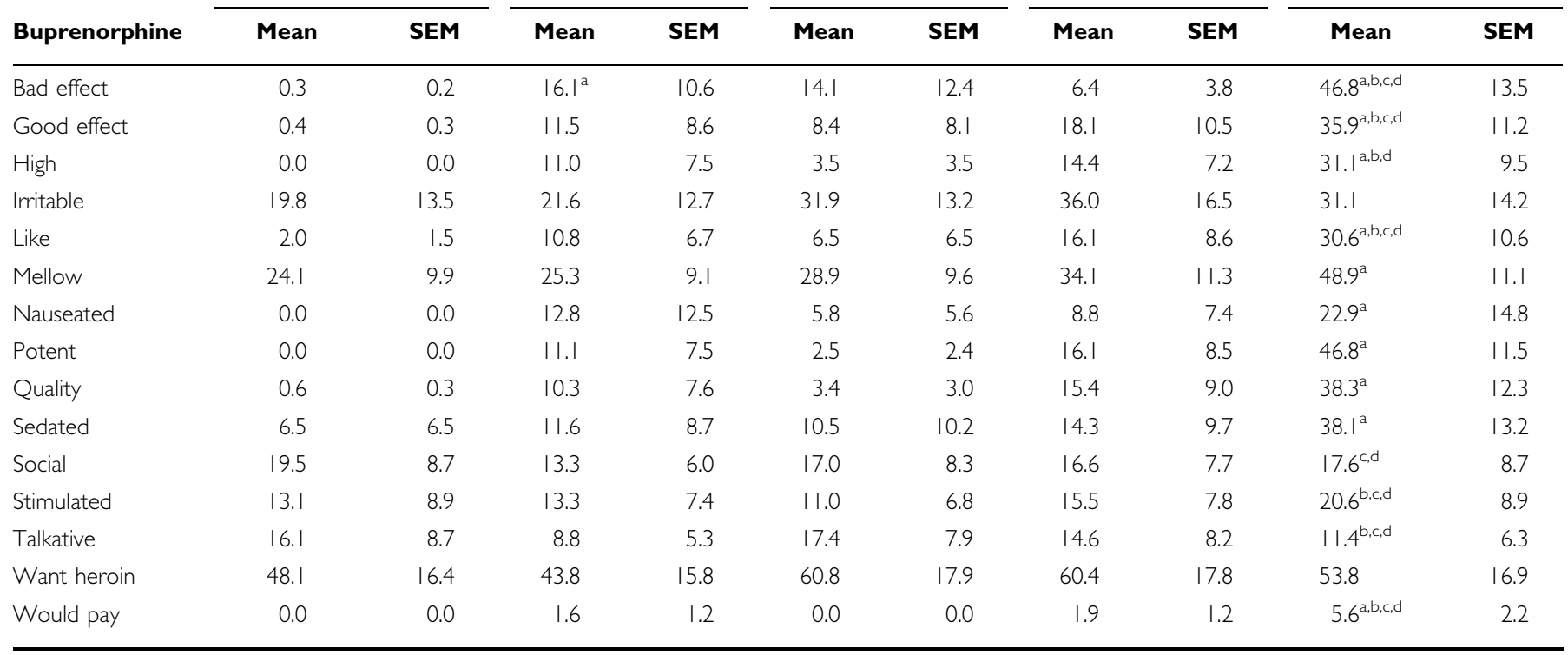

${ }^{\mathrm{a}}$ Significantly different from placebo.

${ }^{\mathrm{b}}$ Significantly different from $12.5 \mathrm{mg} / 70 \mathrm{~kg}$ heroin.

'Significantly different from $50 \mathrm{mg} / 70 \mathrm{~kg}$ morphine.

${ }^{d}$ Significantly different from $50 \mathrm{mg} / 70 \mathrm{~kg}$ oxycodone $(P \leqslant 0.05)$.

the highest dose did not occur for any of the other drugs tested. In contrast to the positive subjective ratings, buprenorphine was the only drug that produced statistically significant increases in VAS ratings of 'I feel a bad drug effect' (bottom panel of Figure 1; Table 1). Please note that this increase occurred in six of the eight participants who 
received the $8 \mathrm{mg} / 70 \mathrm{~kg}$ dose of buprenorphine. Heroin also produced slight increases in peak ratings of 'I feel a bad drug effect,' but these ratings did not reach statistical significance (placebo $(6.0 \mathrm{~mm})$ vs $25 \mathrm{mg} / 70 \mathrm{~kg}$ heroin $\left.(19.4 \mathrm{~mm}): \mathrm{F}_{(1,16)}=2.9, P<0.09\right)$. By contrast, participants rated the $50 \mathrm{mg} / 70 \mathrm{~kg}$ dose of oxycodone as producing no bad drug effects at all (all eight participants scored 0s on this measure). Notably, ratings of 'I feel nauseated' were significantly increased only by buprenorphine at the highest dose tested $(8 \mathrm{mg} / 70 \mathrm{~kg})$. Mean peak ratings of 'I feel mellow,' 'I feel sedated,' and 'The choice was potent' for each drug were similar to the pattern of positive subjective ratings shown in Figure 1.

\section{Drug Effects Questionnaire}

Generally, mean peak ratings of good effect, drug liking, and desire to take the drug again (Figure 2) were similar to the VAS ratings shown in Figure 1 . That is, ratings were generally highest for heroin, morphine, and oxycodone, and lower for fentanyl and buprenorphine across the range of doses tested. Participants reported 'a little' good effect, 'like but not very much,' and 'a little', or 'moderately' interested in taking the drug again for fentanyl and buprenorphine, while they reported 'moderately' good effects, 'like somewhat,' and 'quite a bit' interested in taking the drug again for heroin, morphine, and oxycodone. Interestingly, participants reported similar levels of drug strength for buprenorphine, heroin, morphine, and oxycodone. Fentanyl did not significantly increase ratings of strength of drug effect at any dose tested. Consistent with the VAS, statistically significant increases in ratings of bad drug effects only occurred after administration of buprenorphine (placebo (score of 0.0 ) vs $0.125 \mathrm{mg} / 70 \mathrm{~kg}$ buprenorphine (score of 0.9 ) and $v s 8 \mathrm{mg} / 70 \mathrm{~kg}$ (score of 0.6 ): $\mathrm{F}_{(1,16)}=12.5$, $P<0.0006$ and $\mathrm{F}_{(1,16)}=6.4, P<0.01$, respectively). Participants generally reported that the highest doses of each drug were sedative-like.

\section{Opioid Symptom Checklist}

Sum scores on the Opioid Symptom Checklist were consistent with the pattern of positive subjective responses reported on the VAS and DEQ. All of the drugs produced statistically significant, dose-related increases in sum scores. The highest doses of heroin (score $=5.5, \mathrm{~F}_{(1,16)}=$ 29.6, $P<0.0001$ ), morphine (score $=5.0, \quad \mathrm{~F}_{(1,16)}=29.6$, $P<0.0001), \quad$ oxycodone $\quad\left(\right.$ score $=5.4, \quad F_{(1,16)}=31.7$, $P<0.0001)$, fentanyl (score $\left.=3.9, \mathrm{~F}_{(1,16)}=18.6, P<0.0001\right)$, and buprenorphine $\left(\right.$ score $=4.0, \mathrm{~F}_{(1,16)}=14.1, P<0.0003$ ) were significantly different from placebo (range of sum scores for each drug $=1.0-1.9$ ). For this effect, $50 \mathrm{mg} / 70 \mathrm{~kg}$ heroin $($ score $=5.5)$ produced slightly higher sum scores than $25 \mathrm{mg} / 70 \mathrm{~kg}$ heroin $($ score $=5.0)$.

\section{Subjective Opioid Withdrawal Scales}

Mean peak sum scores on the SOWS were below 10 for all of the drugs and doses tested (SOWS scores could range between 0 and 64). For heroin, the mean peak sum SOWS score for placebo (score $=7.6$ ) was significantly higher than for all of the active doses $(3.125 \mathrm{mg} / 70 \mathrm{~kg}$,

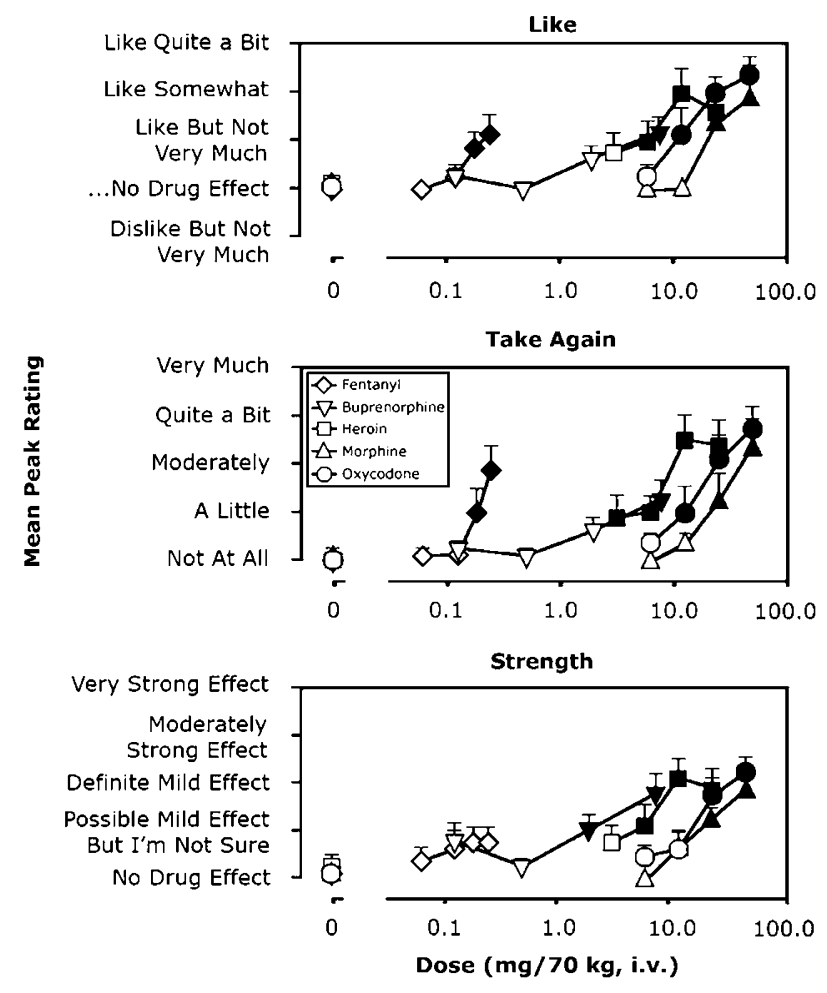

Figure 2 Selected DEQ ratings completed during sample sessions as a function of drug and dose. Data points represent the mean peak ratings \pm I SEM. Filled symbols indicate significant differences from the placebo dose for that drug $(N=8)$.

score $=3.8: \mathrm{F}_{(1,16)}=8.2, P<0.005 ; 6.25 \mathrm{mg} / 70 \mathrm{~kg}$, score $=$ 4.8: $\mathrm{F}_{(1,16)}=4.5, P<0.04 ; 12.5 \mathrm{mg} / 70 \mathrm{~kg}$, score $=4.8: \mathrm{F}_{(1,16)}=$ $4.5, P<0.04 ; 25 \mathrm{mg} / 70 \mathrm{~kg}$, score $\left.=4.5: \mathrm{F}_{(1,16)}=5.3, P<0.02\right)$. There were no significant changes as a function of dose for morphine, oxycodone, or fentanyl. For buprenorphine, the mean peak sum SOWS scores for the $0.5 \mathrm{mg} / 70 \mathrm{~kg}$ and $8 \mathrm{mg} / 70 \mathrm{~kg}$ doses were significantly greater than for placebo (score $=3.6)(0.5 \mathrm{mg} / 70 \mathrm{~kg}$, score $=6.2$ : $\mathrm{F}_{(1,16)}=3.8, P<0.05 ; 8 \mathrm{mg} / 70 \mathrm{~kg}$, score $=9.1: \mathrm{F}_{(1,16)}=16.5$, $P<0.0001)$.

\section{Self-Administration}

Fentanyl, heroin, oxycodone, and morphine all produced dose-related increases in progressive ratio break-point values for drug (left panel of Figure 3). Buprenorphine was not self-administered above placebo levels at any dose tested. Post hoc comparisons revealed that $50 \mathrm{mg} /$ $70 \mathrm{~kg}$ oxycodone produced higher break-point values for drug than $12.5 \mathrm{mg} / 70 \mathrm{~kg}$ heroin $\left(\mathrm{F}_{(1,16)}=3.8, P<0.05\right)$, but $50 \mathrm{mg} / 70 \mathrm{~kg}$ oxycodone did not differ from $50 \mathrm{mg} /$ $70 \mathrm{~kg}$ morphine. Corresponding to the dose-related increases in break-point values for drug, fentanyl, heroin, oxycodone, and morphine all produced dose-related decreases in progressive ratio break-point values for money (right panel of Figure 3). Consistent with the majority of positive subjective-effects ratings, the average progressive ratio break point for $25 \mathrm{mg} / 70 \mathrm{~kg}$ heroin was slightly lower, but not significantly so, than $12.5 \mathrm{mg} / 70 \mathrm{~kg}$ heroin. 

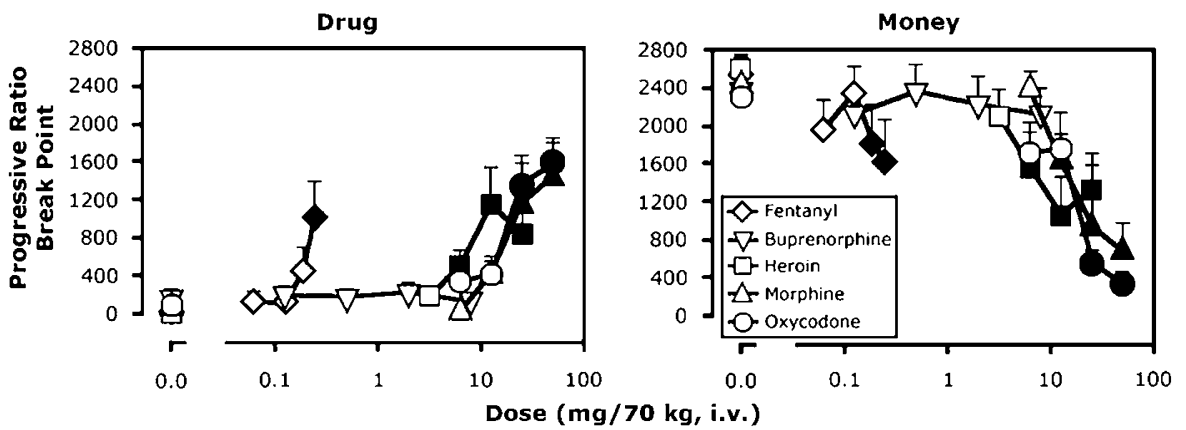

Figure 3 Progressive ratio break-point values for drug (left panel) and money (right panel) during choice sessions as a function of dose and drug. Data points represent the mean values \pm I SEM. Filled symbols indicate significant differences from the placebo dose for that drug $(N=8)$.

\section{Performance Effects}

Under the current experimental conditions, the drugs that were tested produced few systematic effects on task performance, with the exception of the divided attention task.

Divided attention task. Relative to placebo, $50 \mathrm{mg} / 70 \mathrm{~kg}$ oxycodone significantly increased the number of false alarms $\left(\mathrm{F}_{(1,16)}=13.3, P<0.0004\right)$ and the number of missed targets $\left(\mathrm{F}_{(1,16)}=9.6, P<0.002\right)$. On the other hand, relative to placebo, $0.187 \mathrm{mg} / 70 \mathrm{~kg}$ fentanyl significantly decreased the number of false alarms $\left(\mathrm{F}_{(1,16)}=4.2, P<0.04\right)$. Relative to placebo, $25 \mathrm{mg} / 70 \mathrm{~kg}$ heroin significantly decreased the number of correct identifications of a target stimulus (hits) $\left(\mathrm{F}_{(1,16)}=9.7, P<0.002\right)$ and increased the number of missed targets $\left(F_{(1,16)}=9.6, P<0.002\right)$. The maximum speed with which a moving stimulus traveled around the computer screen significantly decreased after administration of $50 \mathrm{mg} / 70 \mathrm{~kg}$ oxycodone compared to placebo $\left(\mathrm{F}_{(1,16)}=9.0\right.$, $P<0.003)$ and the latency to identify a target significantly increased after administration of $25 \mathrm{mg} / 70 \mathrm{~kg}$ heroin $\left(\mathrm{F}_{(1,16)}=5.2, P<0.02\right), 25 \mathrm{mg} / 70 \mathrm{~kg}$ morphine $\left(\mathrm{F}_{(1,16)}=4.6\right.$, $P<0.03), 50 \mathrm{mg} / 70 \mathrm{~kg}$ oxycodone $\left(\mathrm{F}_{(1,16)}=5.9, P<0.02\right)$, or $0.25 \mathrm{mg} / 70 \mathrm{~kg}$ fentanyl $\left(\mathrm{F}_{(1,16)}=6.5, P<0.01\right)$ relative to placebo. The distance between the cursor and the moving stimulus significantly increased after administration of $25 \mathrm{mg} / 70 \mathrm{~kg}$ heroin $\left(\mathrm{F}_{(1,16)}=7.5, \quad P<0.007\right)$, relative to placebo.

\section{Physiological Effects}

Pupil diameter. All of the drugs produced statistically significant, dose-related decreases in mean trough pupil diameter (top left panel of Figure 4). Consistent with the subjective responses, fentanyl and buprenorphine produced the smallest decreases in pupil diameter.

Respiratory measures. Fentanyl, buprenorphine, heroin, and morphine all produced statistically significant decreases in respiratory rate at the higher doses (top right panel of Figure 4). Although respiratory rates after administration of oxycodone were similar in magnitude to the other drugs tested, the results were not statistically significant because the respiratory rate after placebo administration was also somewhat low. The highest doses of heroin, morphine, and oxycodone produced statistically significant decreases in $\% \mathrm{SpO}_{2}$ relative to placebo (bottom left panel of Figure 4). Post hoc comparisons revealed that the decrease in $\% \mathrm{SpO}_{2}$ produced by $25 \mathrm{mg} / 70 \mathrm{~kg}$ heroin was significantly lower than that produced by $50 \mathrm{mg} / 70 \mathrm{~kg}$ morphine $\left(\mathrm{F}_{(1,16)}=10.8, P<0.001\right)$, but not $50 \mathrm{mg} / 70 \mathrm{~kg}$ oxycodone. Fentanyl and buprenorphine did not alter $\% \mathrm{SpO}_{2}$ at any dose tested, relative to placebo. Heroin, morphine, and oxycodone also produced dose-related increases in end tidal $\mathrm{CO}_{2}$ (bottom right panel of Figure 4). Although the active doses of fentanyl and buprenorphine had similar effects on end tidal $\mathrm{CO}_{2}$, the effects of buprenorphine were not significantly different from those of placebo, while those of fentanyl were different from its corresponding placebo condition because end tidal $\mathrm{CO}_{2}$ was somewhat low after placebo administration. For all of the respiratory measures, please note that participants received supplemental oxygen throughout the sample session. These changes in respiration were statistically, but not clinically, significant.

Cardiovascular measures. Average heart rate across the sample session significantly increased from 64.2 to 68.9 b.p.m. after administration of placebo compared to $25 \mathrm{mg} / 70 \mathrm{~kg}$ heroin $\left(\mathrm{F}_{(1,16)}=10.8, P<0.001\right)$. Similarly, average heart rate significantly increased from 63.2 b.p.m. after placebo administration to 70.3 and 70.2 b.p.m. after administration of $25 \mathrm{mg} / 70 \mathrm{~kg}$ and $50 \mathrm{mg} / 70 \mathrm{~kg}$ oxycodone, respectively $\left(\mathrm{F}_{(1,16)}=14.2, P<0.0003 ; \mathrm{F}_{(1,16)}=13.9\right.$, $P<0.0003)$. None of the drugs produced changes in systolic pressure, although the lowest active dose of fentanyl did significantly decrease diastolic pressure relative to placebo (placebo: $68.5 \mathrm{mmHg}$; $0.0625 \mathrm{mg} / 70 \mathrm{~kg}$ fentanyl: $64.0 \mathrm{mmHg}$; $\left.\mathrm{F}_{(1,16)}=3.9, P<0.05\right)$.

\section{DISCUSSION}

One important outcome of the present study was that buprenorphine did not serve as a reinforcer, even at doses that produced statistically significant increases in positive subjective ratings. In several previous studies conducted in our laboratory, buprenorphine did serve as a robust reinforcer (Comer et al, 2002, 2005; Comer and Collins, 2002). The primary difference among the studies is that participants were maintained on morphine in the present 

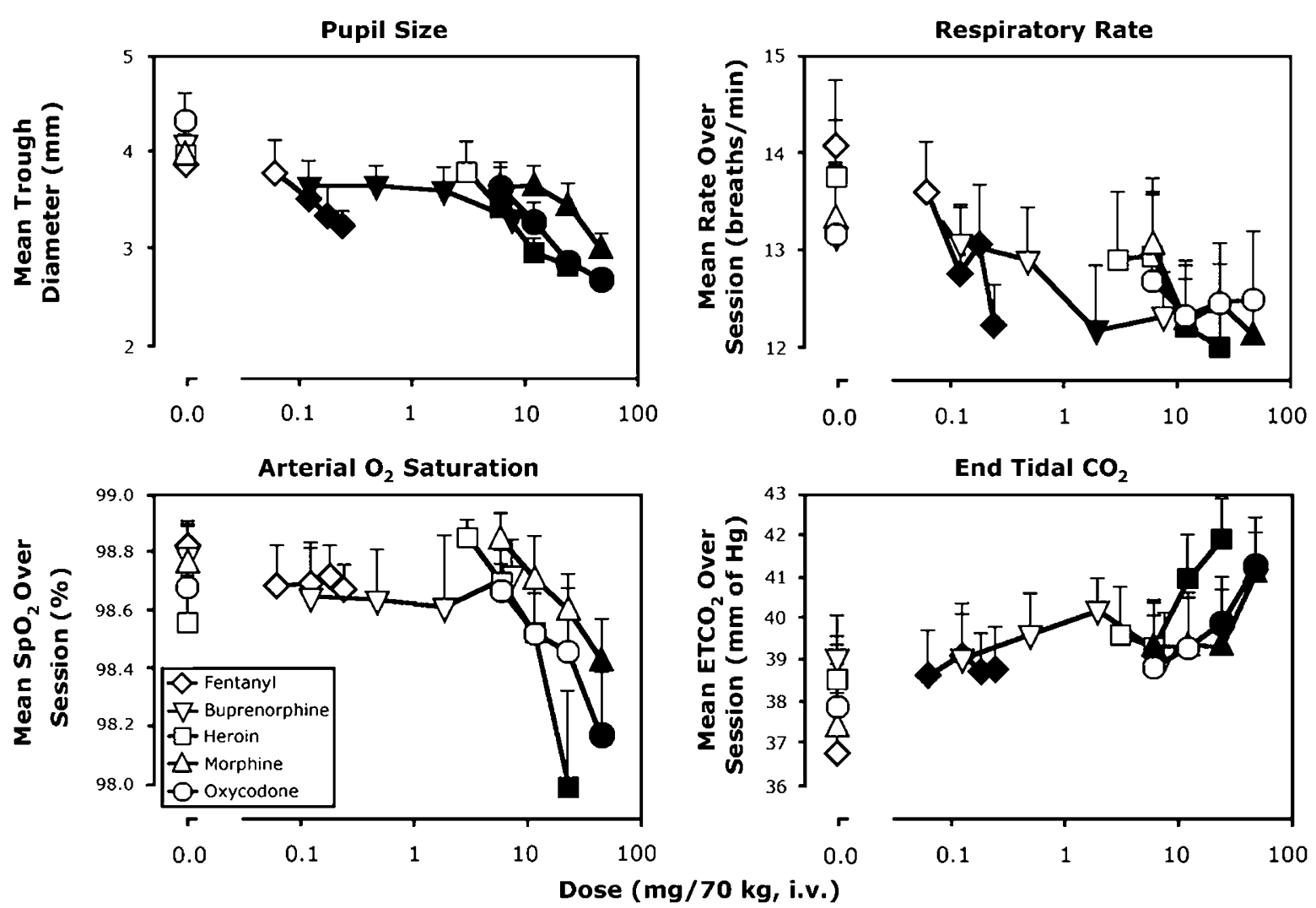

Figure 4 Selected physiological responses collected during sample sessions as a function of dose and drug. Data points represent mean trough pupil size (top left panel) and mean respiratory effects (all other panels). The lowest (trough) pupil diameter after drug administration was obtained for each participant and then these values were averaged across participants. For the respiratory measures, the average value across the session after drug administration was obtained for each participant and then these values were averaged across participants. Filled symbols indicate significant differences from the placebo dose for that drug $(N=8)$.

experiment. This overall pattern of effect across our studies is consistent with research conducted in rhesus monkeys showing that the reinforcing effects of buprenorphine are reduced to a greater extent than those of other mu opioid agonists in animals treated chronically with morphine (Winger and Woods, 2001). In that study, alfentanil, heroin, morphine, buprenorphine, and nalbuphine all served as reinforcers under control (ie non-opioid-dependent) conditions. However, when the animals were treated chronically with morphine, the potency of alfentanil was unchanged and the potencies of heroin and morphine were reduced only slightly. In contrast, both the potency and reinforcing effectiveness of buprenorphine and nalbuphine were reduced substantially. Similar results have been obtained for the analgesic and discriminative stimulus effects of buprenorphine relative to other mu opioid agonists (eg Walker and Young, 2001). Combined, these data suggest that the abuse liability of buprenorphine may be relatively low in heroin-dependent individuals. In the United States, the buprenorphine/naloxone combination tablet is used most frequently for treating opioid dependence. The combination tablet theoretically should have even less abuse liability than the buprenorphine alone product in heroin-dependent individuals (eg Mendelson et al, 1996). Future studies will examine this important question.

It is possible that participants failed to find buprenorphine reinforcing in the present study because it precipitated mild opioid withdrawal. Subjective ratings of withdrawal were slightly elevated after administration of the lowest and highest doses of buprenorphine. Interestingly, despite this outcome, peak subjective ratings of good drug effects, drug liking, high, and quality of drug effects significantly increased after administration of the highest dose of buprenorphine. Several studies in opioid-dependent laboratory animals showed that buprenorphine precipitated and/or exacerbated withdrawal (Woods and Gmerek, 1985; Woods et al, 1992; Yanagita et al, 1982). In contrast, the ability of buprenorphine to precipitate withdrawal in opioid-dependent humans is less clear. Buprenorphine precipitated moderate to severe withdrawal in patients maintained on $60 \mathrm{mg}$ methadone (Walsh et al, 1995). In contrast, sublingual doses between 2 and $8 \mathrm{mg}$ buprenorphine produced either no or mild withdrawal in either heroin-dependent or methadone-maintained $(25-30 \mathrm{mg})$ individuals (Kosten and Kleber, 1988; Kosten et al, 1991; Strain et al, 1992; Walsh et al, 1995). In fact, buprenorphine significantly increased ratings of 'Good Effects' and feelings of 'Overall Well-being,' and decreased ratings of 'Overall Sickness' by heroin-dependent men who received increasing doses of buprenorphine during a rapid dose induction onto buprenorphine maintenance (Johnson et al, 1989). In this study, buprenorphine was consistently identified as an opioid agonist, rather than an antagonist. Intravenous administration of buprenorphine $(2 \mathrm{mg})$ to 
heroin-dependent individuals also increased ratings of 'Good Effects' and drug 'Liking,' without precipitating withdrawal (Mendelson et al, 1996). Likewise, intramuscular administration of buprenorphine $(6 \mathrm{mg})$ to individuals maintained on morphine failed to precipitate withdrawal (Schuh et al, 1996). In this study, when participants were maintained on low doses of morphine (15 or $30 \mathrm{mg} /$ day), buprenorphine significantly increased ratings of 'High,' 'Good Effects,' and 'Liking.' These positive subjective ratings did not significantly differ after buprenorphine compared to placebo administration in individuals maintained on 60 or $120 \mathrm{mg} /$ day morphine. In addition to the maintenance drug and maintenance dose, the time since the last dose of the maintenance drug also appears to be an important factor in the ability of buprenorphine to precipitate withdrawal. Withdrawal occurred in patients maintained on $30 \mathrm{mg}$ methadone when buprenorphine was administered $2 \mathrm{~h}$, but not $20 \mathrm{~h}$, after the last methadone dose (Strain et al, 1992, 1995). It is possible that differences in the maintenance drug, dose, and time since the last maintenance dose administration contributed to the slightly different outcomes in the present study compared to previous studies.

Nevertheless, the current data provide empirical evidence for the importance of evaluating both subjective responses and drug-taking behavior. With buprenorphine, a combination of positive and negative subjective responses was reported, which suggested that it might have lower abuse liability than the other medications tested. The behavioral measure helped to clarify this issue by showing that participants did not choose to take drug under any dose tested, even those that produced significant increases in positive subjective effects. Although it is possible that yet higher doses of buprenorphine would have produced some reinforcing effects, we were reluctant to increase the dose in the present study because we were not sure how severe the withdrawal syndrome would be under these experimental conditions.

Another important finding from the present study is that the abuse liability of oxycodone appears to be substantial. Oxycodone produced robust reinforcing effects, similar to those of morphine and heroin, and it produced some of the most robust increases in positive subjective ratings, but no increases in ratings of bad effects. Given that a balance of positive and negative subjective ratings is likely to influence the degree to which a drug is abused, the fact that oxycodone produced virtually no negative effects in heroin abusers is particularly concerning. Our research finding is consistent with verbal reports from heroin-dependent individuals, who have stated that oxycodone is the 'Rolls Royce' of opioids and that it produces a 'smooth' high. Although it was not possible to differentiate the relative reinforcing effects of fentanyl, oxycodone, morphine, and heroin in the present study, an ongoing study in our laboratory is utilizing a drug-vs-drug choice procedure in an attempt to more fully characterize the relative abuse liabilities of oxycodone and morphine. In this study, the effects of oral oxycodone and morphine are being compared to more closely parallel the epidemiological data showing that the abuse of these medications occurs most often via the oral route (SAMHSA, 2006).
One variable that may have influenced the reinforcing effects of the medications that were tested in the present study was the duration of action of each of the drugs. In the current study, complete pharmacodynamic characterizations of the time course of each medication were not performed. However, a previous study showed that the time course of oral oxycodone and morphine was similar (Zacny and Gutierrez, 2003). Because heroin is rapidly metabolized to morphine, the time course of effects for these two drugs is likely to be similar (see Comer et al, 1999; Jasinski and Preston, 1986). Therefore, it may be safe to assume that the durations of action of heroin, morphine, and oxycodone are similar. The duration of action of intravenous buprenorphine, on the other hand, is somewhat longer than that of the other medications (eg Comer et al, 2002; Nath et al, 1999) and the duration of action of intravenous fentanyl is shorter (Zacny et al, 1992, 1996a, b). It is possible that the long duration of action of buprenorphine contributed to its lack of reinforcing effects. That is, the morning sample dose may have still been effective during the afternoon choice session so that participants did not feel that they 'needed' it in the afternoon. This outcome is unlikely; however, because a previous study conducted in our laboratory showed that when buprenorphine was available during choice sessions in the morning and the afternoon, participants self-administered roughly the same amount of buprenorphine during both choice sessions (Comer et al, 2002; Comer and Collins, 2002). The shorter duration of action produced by fentanyl also may have altered its reinforcing effects. However, a previous study conducted in rhesus monkeys comparing self-administration of fentanyl, alfentanil, and remifentanil suggested that the duration of drug action may not be an important factor in the reinforcing strength of a drug (Ko et al, 2002).

With regard to physiological effects, all of the drugs produced statistically significant decreases in pupil diameter, as expected. Although active doses of buprenorphine produced miosis, relative to placebo, the dose-response function for buprenorphine appeared to be shallower than for the other drugs tested, which is consistent with its partial agonist profile. End tidal $\mathrm{CO}_{2}$ and $\% \mathrm{SpO}_{2}$ were not significantly altered by any of the active doses of buprenorphine tested, although respiratory rate was slightly reduced by $2 \mathrm{mg} / 70 \mathrm{~kg}$ buprenorphine. These data again are consistent with the partial agonist profile of buprenorphine. Like buprenorphine, the highest doses of fentanyl that were tested also produced statistically significant decreases in pupil diameter. However, $\% \mathrm{SpO}_{2}$ after fentanyl administration was not significantly different from placebo. Although the doses of fentanyl were chosen a priori based on safety considerations, examination of the entire data set suggests that the doses of fentanyl that we chose for the present study were moderate. Nevertheless, it is clear that the overall pattern of effect produced by fentanyl was more similar to the full agonists than to buprenorphine. The physiological effects of oxycodone were either equipotent with morphine (eg end tidal $\mathrm{CO}_{2}$ ) or in between those produced by morphine and heroin (eg pupil diameter, $\left.\% \mathrm{SpO}_{2}\right)$. The absolute magnitude of effects produced by oxycodone, heroin, and morphine was similar.

With regard to task performance, the results of the present study were similar to those obtained in our previous 
studies. That is, none of the opioids produced robust impairments in task performance. The divided attention task was the only one in which consistent disruptions in performance were obtained. Interestingly, buprenorphine was the only drug that did not produce any impairments in performance of the divided attention task. In two of our previous studies in non-opioid-dependent individuals, buprenorphine did produce impairments in performance of the DAT (Comer et al, 2002, 2005), but it did not significantly impair performance of the DAT in a third study (Comer and Collins, 2002). A final interesting finding in the present study was the improvement in performance of the DAT after fentanyl administration. However, it is not clear why this effect occurred.

In summary, the present results demonstrate that the reinforcing effects of intravenously administered buprenorphine may be quite low in heroin-/morphine-dependent individuals because it precipitates mild opioid withdrawal. However, it is unclear whether the same is true in buprenorphine-dependent individuals. This question awaits future research. The present data also lend further support for the safety of buprenorphine in that it produced the smallest decreases in respiratory measures and it did not significantly disrupt task performance. Consistent with previous studies, our data suggest that buprenorphine is an excellent medication for the treatment of opioid dependence because it is safe, well tolerated, and may have relatively low abuse potential, especially in heroin-dependent individuals. In contrast to this finding for buprenorphine, the present data suggest that oxycodone may have substantial abuse liability in opioid-dependent individuals. A number of epidemiological studies have shown that oxycodone is one of the most widely abused prescription opioids. However, it is not clear from these studies whether the widespread abuse of oxycodone is due to the fact that it is easily available or whether something about its pharmacology makes it more likely to be abused. The present results suggest that the pharmacology of oxycodone is quite similar to that of other highly abused opioid medications, such as morphine and fentanyl, and to the 'street drug,' heroin. Of particular concern was the finding that oxycodone produced so few reports of 'bad drug effects,' suggesting that its pharmacological profile, coupled with its ready availability, may contribute to the high prevalence of abuse of this particular medication.

\section{ACKNOWLEDGEMENTS}

We gratefully acknowledge the medical assistance of Janet Murray RN, Benjamin Nordstrom MD, Shabnam Shakibaie MD, and John Mariani MD and the technical assistance of Chaim Kozlovski BS, Jessica Houser BS, and Samuel Krug. This research was supported by National Institute on Drug Abuse Grant DA09236.

\section{DISCLOSURE/CONFLICT OF INTERESTS}

SD Comer serves as a consultant on issues related to the abuse liability of opioid medications to Janssen Pharmaceuticals, Johnson \& Johnson Pharmaceutical Research and Development, L.L.P., Schering-Plough Corporation, and
Grunenthal $\mathrm{GmbH}$. In addition, she received funding from Grunenthal $\mathrm{GmbH}$ to conduct two investigator-initial trials on prescription opioid abuse liability.

\section{REFERENCES}

Amass L, Kamien JB, Reiber C, Branstetter SA (2000). Abuse liability of IV buprenorphine-naloxone, buprenorphine, and hydromorphone in buprenorphine-naloxone maintained volunteers. Drug Alcohol Depend 60(Suppl 1): S6-S7.

Beardsley PM, Aceto MD, Cook CD, Bowman ER, Newman JL, Harris LS (2004). Discriminative stimulus, reinforcing, physical dependence, and antinociceptive effects of oxycodone in mice, rats, and rhesus monkeys. Exp Clin Psychopharmacol 12: 163-172.

Comer SD, Collins ED (2002). Self-administration of intravenous buprenorphine and the buprenorphine/naloxone combination by recently detoxified heroin abusers. J Pharmacol Exp Ther 303: 695-703.

Comer SD, Collins ED, Fischman MW (1997). Choice between money and intranasal heroin in morphine-maintained humans. Behav Pharmacol 8: 677-690.

Comer SD, Collins ED, Fischman MW (2002). Intravenous buprenorphine self-administration by detoxified heroin abusers. J Pharmacol Exp Ther 301: 266-276.

Comer SD, Collins ED, MacArthur RB, Fischman MW (1999). Comparison of intravenous and intranasal heroin self-administration by morphine-maintained humans. Psychopharmacology 143: 327-338.

Comer SD, Collins ED, Wilson ST, Donovan MR, Foltin RW, Fischman MW (1998). Effects of an alternative reinforcer on i.v. heroin self-administration by humans. Eur J Pharmacol 345: 13-26.

Comer SD, Sullivan MA, Walker EA (2005). Comparison of intravenous buprenorphine and methadone self-administration by recently detoxified heroin-dependent individuals. J Pharmacol Exp Ther 315: 1320-1330.

Foley KM (1985). The treatment of cancer pain. N Engl J Med 313: 84-95.

Jasinski DR, Preston KL (1986). Comparison of intravenously administered methadone, morphine, and heroin. Drug Alcohol Depend 17: 301-310.

Johnson RE, Cone EJ, Henningfield JE, Fudala PJ (1989). Use of buprenorphine in the treatment of opiate addiction. I. Physiologic and behavioral effects during a rapid dose induction. Clin Pharmacol Ther 46: 335-343.

Johnston LD, O’Malley PM, Bachman JG, Schulenberg JE (2006). Monitoring the Future National Results on Adolescent Drug Use: Overview of Key Findings, 2005 (NIH Publication No. 06-5882). National Institute on Drug Abuse: Bethsda, MD.

Ko MC, Terner J, Hursh S, Woods JH, Winger G (2002). Relative reinforcing effects of three opioids with different durations of action. J Pharmacol Exp Ther 301: 698-704.

Kosten TR, Kleber HD (1988). Buprenorphine detoxification from opioid dependence: a pilot study. Life Sci 42: 635-641.

Kosten TR, Morgan C, Kleber HD (1991). Treatment of heroin addicts using buprenorphine. Am J Drug Alcohol Abuse 17: 119-128.

Manner T, Kanto J, Salonen M (1987). Simple devices in differentiating the effects of buprenorphine and fentanyl in healthy volunteers. Eur J Clin Pharmacol 31: 673-676.

Mello NK, Lukas SE, Bree MP, Mendelson JH (1988). Progressive ratio performance maintained by buprenorphine, heroin and methadone in Macaque monkeys. Drug Alcohol Depend 21: 81-97.

Mendelson J, Jones RT, Fernandez I, Welm S, Melby AK, Baggott MJ (1996). Buprenorphine and naloxone interactions 
in opiate-dependent volunteers. Clin Pharmacol Ther 60: $105-114$

Morgan AD, Campbell UC, Fons RD, Carroll ME (2002). Effects of agmatine on the escalation of intravenous cocaine and fentanyl self-administration in rats. Pharmacol Biochem Behav 72: 873-880

Nath RP, Upton RA, Everhart ET, Cheung P, Shwonek P, Jones RT. et al (1999). Buprenorphine pharmacokinetics: relative bioavailability of sublingual tablet and liquid formulations. J Clin Pharmacol 39: 619-623.

SAMHSA (2004a). Office of Applied Studies. Results from the 2003 National Survey on Drug use and Health: National Findings. NSDUH Series H-25, DHHS Publication No. SMA 04-3964. Department of Health and Human Services (DHHS): Rockville, MD.

SAMHSA (2004b). Office of Applied Studies. The DAWN Report: Narcotic Analgesics, Department of Health and Human Services (DHHS), 2002 update.

SAMHSA (2004c). Office of Applied Studies Drug Abuse Warning Network, 2003: Interim National Estimates of Drug-Related Emergency Department Visits. DAWN Series D-26, DHHS Publication No. (SMA) 04-3972. Department of Health and Human Services (DHHS): Rockville, MD.

SAMHSA (2005a). Office of Applied Studies. Results from the 2004 National Survey on Drug use and Health: National Findings. NSDUH Series H-28, DHHS Publication No. SMA 05-4062. Department of Health and Human Services (DHHS): Rockville, MD.

SAMHSA (2005b). Office of Applied Studies. Treatment Episodes Data Set (TEDS): 1993-2003. National Admissions to Substance Abuse Treatment Services. DASIS Series: S-29 DHHS Publication No. SMA 05-4118. Department of Health and Human Services (DHHS): Rockville, MD.

SAMHSA (2006). Office of Applied Studies. Treatment Episodes Data Set (TEDS): Highlights-2005. National Admissions to Substance Abuse Treatment Services. DASIS Series: S-36, DHHS Publication No. SMA 07-4229. Department of Health and Human Services (DHHS): Rockville, MD.

Schuh KJ, Walsh SL, Bigelow GE, Preston KL, Stitzer ML (1996). Buprenorphine, morphine and naloxone effects during ascending morphine maintenance in humans. J Pharmacol Exp Ther 278: $836-846$.

Strain EC, Preston KL, Liebson IA, Bigelow GE (1992). Acute effects of buprenorphine, hydromorphone and naloxone in methadone-maintained volunteers. J Pharmacol Exp Ther 261: 985-993.
Strain EC, Preston KL, Liebson IA, Bigelow GE (1995). Buprenorphine effects in methadone-maintained volunteers: effects at two hours after methadone. J Pharmacol Exp Ther 272: 628-638.

Walker EA, Young AM (2001). Differential tolerance to antinociceptive effects of mu opioids during repeated treatment with etonitazene, morphine, or buprenorphine in rats. Psychopharmacology 154: 131-142.

Walsh SL, June HL, Schuh KJ, Preston KL, Bigelow GE, Stitzer ML (1995). Effects of buprenorphine and methadone in methadonemaintained subjects. Psychopharmacology 119: 268-276.

Winger G, Woods JH (2001). The effects of chronic morphine on behavior reinforced by several opioids or by cocaine in rhesus monkeys. Drug Alcohol Depend 62: 181-189.

Woods JH, France CP, Winger GD (1992). Behavioral pharmacology of buprenorphine: issues relevant to its potential in treating drug abuse. In: Blaine JD (ed). Buprenorphine: An Alternative Treatment for Opioid Dependence (National Institute on Drug Abuse Research Monograph, No 121). US Government Printing Office: Washington DC, pp 12-27.

Woods JH, Gmerek DE (1985). Substitution and primary dependence studies in animals. Drug Alcohol Depend 14: 233-247.

Woods JH, Ko MC, Winger G, France CP, Traynor JR (2002). Evaluation of new compounds for opioid activity. In: Dewey WL and Harris LS (eds). NIDA Research Monograph, Vol. 183. NIDA: Rockville, MD, USA. pp 170-190.

Yanagita T, Katoh S, Wakasa Y, Oinuma N (1982). Dependence potential of buprenorphine studied in rhesus monkeys. In: Harris LS (ed). Problems of Drug Dependence 1981 Proceeding of the 43rd Annual Scientific Meeting (National Institute on Drug Abuse Research Monograph, No. 41). US Government Printing Office: Washington DC, pp 208-214.

Zacny JP, Coalson DW, Klafta JM, Klock PA, Alessi R, Rupani G et al (1996a). Midazolam does not influence intravenous fentanyl-induced analgesia in healthy volunteers. Pharmacol Biochem Behav 55: 275-280.

Zacny JP, Gutierrez S (2003). Characterizing the subjective, psychomotor, and physiological effects of oral oxycodone in non-drug-abusing volunteers. Psychopharmacology 170: 242-254.

Zacny JP, Lichtor JL, Zaragoza JG, de Wit H (1992). Subjective and behavioral responses to intravenous fentanyl in healthy volunteers. Psychopharmacology 107: 319-326.

Zacny JP, McKay MA, Toledano AY, Marks S, Young CJ, Klock PA et al (1996b). The effects of a cold-water immersion stressor on the reinforcing and subjective effects of fentanyl in healthy volunteers. Drug Alcohol Depend 42: 133-142. 